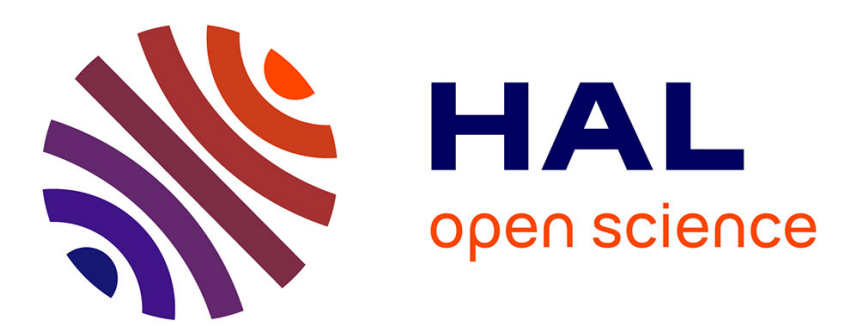

\title{
Russian Logics and the Culture of Impossible: PART I, Recovering Intelligentsia Logics
}

\author{
Ksenia Tatarchenko, Anya Yermakova, Liesbeth de Mol
}

\section{To cite this version:}

Ksenia Tatarchenko, Anya Yermakova, Liesbeth de Mol. Russian Logics and the Culture of Impossible: PART I, Recovering Intelligentsia Logics. IEEE Annals of the History of Computing, 2021, Logic and Computation, 43, pp. 43-56. hal-03081260

\section{HAL Id: hal-03081260 \\ https://hal.univ-lille.fr/hal-03081260}

Submitted on 30 Aug 2021

HAL is a multi-disciplinary open access archive for the deposit and dissemination of scientific research documents, whether they are published or not. The documents may come from teaching and research institutions in France or abroad, or from public or private research centers.
L'archive ouverte pluridisciplinaire HAL, est destinée au dépôt et à la diffusion de documents scientifiques de niveau recherche, publiés ou non, émanant des établissements d'enseignement et de recherche français ou étrangers, des laboratoires publics ou privés. 


\title{
Russian Logics and the Culture of Impossible:
}

\section{PART I, Recovering Intelligentsia Logics ${ }^{1}$}

\author{
Ksenia Tatarchenko \\ Anya Yermakova \\ Liesbeth De Mol
}

This paper reinterprets algorithmic rationality by looking at the interaction between mathematical logic, mechanized reasoning and, later, computing in the Russian Imperial and Soviet contexts to offer a history of the algorithm as a mathematical object bridging the inner and outer worlds, a humanistic vision that we, following logician Vladimir Uspensky, call the "culture of the impossible.” We unfold the deep roots of this vision as embodied in scientific intelligentsia. In Part I, we examine continuities between the turnof-the-twentieth-century discussions of poznaniye -- an epistemic orientation towards the process of knowledge acquisition -- and the postwar rise of the Soviet school of mathematical logic. Establishing this connection allows us to explain, in Part II, the role of the algorithm in disciplinary dynamics between mathematical logic and cybernetics and a characteristic understanding of programming, not as a narrow skill, but as a matter of consciousness.

Keywords: algorithm, logic, cybernetics, Soviet Union, Cold War, Vladimir Uspensky

\section{Introduction}

That the ascendency of algorithm in current society has a history needs little defense. That such a history misses its Russian and Soviet parts is, however, a proposition to be explained on several accounts. ${ }^{2}$ The current debates on algorithmic decision making and the promises of artificial intelligence are incomplete without restoring a Russian and Soviet history of algorithms as mathematical objects of a

1 This is a draft version of part I of a paper to be published in the special issue "Logic, programming and the shaping of computer science: National and Local Perspectives" of the IEEE Annals for the History of Computing 2 Here and in the rest of the article, we acknowledge that the use of the term "Russian" is not uncomplicated. Just as the term "Soviet" or "post-Soviet" may gloss over the diversity of national, ethnic, and cultural voices within the former USSR - together with complex and understudied relations between the colonizer and the colonized within this Eurasian territory - the term "Russian" may elicit erasure of the multiple identities that were in their times or in their ancestral lineage absorbed by the russophone hierarchy or subject to russification policies and practices. We attempt to bypass the normative use of "Russian" to indiscriminately refer to both ethnically Russian people and people living in the former Russian Empire or the USSR. We use "russophone” or "Russian-language” for specifically linguistic referents and "Russian Imperial” or "Soviet” for explicitly political referents. Most importantly, this narrative includes both ethnically Russian and non-Russian characters. When referring to a person as "Russian," we do so only if, to the best of our knowledge, that person was of Russian ethnicity. When using the term "Russian" as a general category, we do not imply erasure of the multiplex identities of characters woven into this article. We acknowledge the relatively impoverished vocabulary for discussing the entangled, multiplex, and invisible identities beneath the term, and advocate for extension of postcolonial and diasporic studies in the histories of Russia and Eurasia. For a deeper discussion see T. Koplatadze, “Theorising Russian Postcolonial Studies,” Postcolonial Studies 22, no. 4, Oct 2019, pp. 469-89. 
particular kind, namely involving a humanistic preoccupation with judgement and meaning. Typically, today's critical discussions of the politics of algorithms are predicated on their role in digital information systems and databases, and address their social ramifications via this technical bias. ${ }^{3}$ Instead, in the Russian context, algorithms are inscribed in a general vision of educating and shaping human minds. Thus, algorithms were not only imbued with cultural and political valances as special mathematical objects but were also conceived as mediators of human-machine interaction linking the capacity of abstract thinking to the power of a goal-oriented action. The two parts of this article unfold the specific national context generating a humanistic vision of the algorithm that we call the "culture of impossible" by borrowing from the 2011 brochure "The Mathematical and the Humanities: Overcoming the Barrier" by Vladimir Uspensky (1930-2018). ${ }^{4}$ The two parts also share a historiographic ambition to reinscribe the russophone intellectual developments into the global context to which they belonged.

To show deep roots of this understanding of algorithm we ground our study in a longue durée perspective. Our focus on the phenomenon of "intelligentsia scientist," characterized by Michael Gordin and Karl Hall as defining the century of Russian science from 1860s to 1960s, reveals important continuities between the late Soviet way of approaching logico-mathematical objects as a means of inculcating patterns of thinking and the debates about "critically thinking individuals" in Russian Imperial society since the mid-19th century. ${ }^{5}$ In Part I, we reveal intellectual, social, and cultural continuities between the turn-of-the-century discussions of poznaniye -- an epistemic orientation towards the process of knowledge acquisition rather than knowledge as such -- and the rise of the Soviet school of mathematical logic in the post-WWII period. Establishing this connection allows us to explain the disciplinary dynamics between mathematical logic and cybernetics that contributed to a characteristic late Soviet preoccupation with computerization and programming as a matter of consciousness. This will be elaborated in Part II by focusing on the life and work of Vladimir Uspensky, a Russian logician and a major contributor to the development of the theory of algorithms as well as a key actor in institutional and informal networks.

Unlike genetics, nuclear physics or the space program, Soviet mathematical logic has attracted little attention among historians writing in English. ${ }^{6}$ The most accessible historical account was produced by community members, including Uspensky, and privileges the universality of the intellectual agenda of the field as a response to the turn-of-the-century crisis in foundations of mathematics. ${ }^{7}$ Such narratives highlight the pioneering contributions to mathematical logic by Andrey Kolmogorov (1903-1987), Andrey Markov Jr. (1903-1979), and Petr Novikov (1901-1975), as well as those of their students. Although informative, this contribution-focused account of mathematical genealogies omit more general motivations for studying, teaching, and developing what came to be termed "algorithmic" and explain neither what appears as a sudden rise of the Soviet school of mathematical logic nor its preoccupation with the algorithm as a way of human thinking. ${ }^{8}$

Revealing continuities between the work of these father-figures and earlier, pre-revolutionary intellectual traditions is not simply a matter of retracing a history of disciplinary formation, however. On

3 Safiya Umoja Noble, Algorithms of Oppression: How Search Engines Reinforce Racism, New York: NYU Press, 2018.

4 V. Uspensky, Matematicheskoe i gumanitarnoe: preodolenie bar'era [The Mathematical and the Humanities: Overcoming the Barrier], Moscow: MTsMNO, 2011.

5 M. Gordin, K. Hall, “Introduction: Intelligentsia Science Inside and Outside Russia,”

Intelligentsia Science: The Russian Century, 1860-1960, Osiris 23, edited by M. Gordin, K. Hall, \& A. Kojevnikov, Chicago: The University of Chicago Press, 2008, pp. 1-19, on p. 2.

6 See I. Anellis, "Mathematical logic in the Soviet Union, 1917-1980," History and Philosophy of Logic: Vol. 8, No. 1, pp. 71-76, for a comprehensive overview that is in need of an update.

7 For an example, see: V. Uspensky, "Kolmogorov and Mathematical Logic," The Journal of Symbolic Logic 57, no. 2 (1992): 385-412,

8 On "algorithmic thinking" as an actor category in both the Soviet and international settings, see: K. Tatarchenko, "Thinking Algorithmically: From Cold War Computer Science to the Socialist Information Culture," Historical Studies in the Natural Sciences, vol. 49, no. 2, 2019, pp. 194-225. 
the one hand, the field of mathematical logic in the pre-war Soviet Union belongs among the long list of sciences victimized by the Soviet regime. On the other hand, its later, post-war institutionalization took place in the context of metadisciplinary discussions about a novel intellectual development, that of cybernetics. Moreover, some of the challenges in providing a contextualized interpretation of works in mathematical logic are not specific to Russian-language materials but to the general methodological challenges of studying non-observational scientific practice. ${ }^{9}$ Yet, this methodological challenge explains the difficulty of dealing with Russian-language material but not the normative status of its omission. In fact, such an omission was cemented by the common usage of narratives about the US-American developments related to computing to stand in for all developments during the Cold War. ${ }^{10}$ Meanwhile, the Soviet history of computing has disappeared into the hardware gap narrative.

To make direct genealogical arguments about pre-revolutionary roots of the "culture of impossible," we are opting for a methodological combination of the history of ideas and biographical approaches. Whereas a synthetic overview of key nineteenth century concepts and figures provides a general intellectual landscape, a narrower biographical scale embodies the notion of "intelligentsia scientist." Tracing a series of interpersonal interactions leads us to broader patterns which suggest that concepts, ideas, and pedagogical practices connected to the mathematical object of the algorithm are in accord with pre-Soviet and early Soviet intelligentsia cultural capital of "word and deed," in which life of the mind is equated to political action. The conceptual continuity is evident in the humanities-centric perception of mathematics, the performative pedagogical culture in math and logic, and the socially significant understanding of abstraction. Thus, the focus on circulating mathematical objects such as the Law of Excluded Middle (LEM) and the algorithm, and on the research and educational practices in which those objects were embedded, opens avenues for historiographic revision. ${ }^{11}$

The dominant narrative of current historiography posits that current fascination with the algorithm has Cold War origins: the rise of algorithmic reasoning was coterminous with American intellectuals and politicians striving for optimal decision making under nuclear threat. ${ }^{12}$ Characteristically, the Cold War here refers to the experiences of the Western world. In How Reason Almost Lost its Mind: The Strange Career of Cold War Rationality, the authors offer broad and insightful arguments, in which algorithmic rationality is taken as an analytical construction. This allows them to elucidate the shift from the values of Enlightenment to those of Cold War, from the practices of deliberation to the mechanical application of rules--the rules denigrating the status of human judgements and implying that computers might reason better than humans. Although the contributors to How Reason Almost Lost its Mind occasionally refer to Soviet discussions of the algorithm during the period, this happens mostly in the footnotes, where Soviet definition of the algorithm (namely its definiteness, generality, and conclusiveness) is acknowledged only insofar as it is embraced by the American participants in the

9 On the methodological challenges of inquiring into "thought experiments" characteristic of mathematical work, see: A. Alexander, "The Skeleton in the Closet: Should Historians of Science Care about the History of Mathematics?” Isis, vol. 102, no. 3, Sept. 2011, pp. 475-80; and P. Galison, “Ten Problems in History and Philosophy of Science,” Isis 99 (2008), pp. 111-124. On material practices in mathematics, see: Matthew L. Jones, Reckoning with matter: Calculating machines, innovation, and thinking about thinking from Pascal to Babbage, Chicago: University of Chicago Press, 2016. Particularly relevant to our approach is the work on algorithms as texts and sequences of actions in the Chinese context, see: Karine Chemla, "Describing Texts for Algorithms: How They Prescribe Operations and Integrate Cases. Reflections Based on Ancient Chinese Mathematical Sources," in Texts, Textual Acts and the History of Science, Springer, Cham, 2015, pp. 317-384.

10 The classical account by Paul Edwards is representative of this ongoing trend: P. Edwards, The Closed World: Computers and the Politics of Discourse in Cold War America, Cambridge: MIT Press, 1996.

11 Though not a material object, the LEM is an epistemic object we consider to have the capacity to be circulated, much as and alongside the diverse types of non-material objects that contribute to circulation of knowledge. See J. Östling, E. Sandmo, D. Larsson Heidenblad, A. Nilsson Hammar, K. Nordberg, eds., Circulation of Knowledge: Explorations in the History of Knowledge. Nordic Academic Press, 2018.

12 P. Erickson, J. Klein, L. Daston, R. Lemov, Th. Sturm, and M. Gordin, eds., How Reason Almost Lost its Mind: The Strange Career of Cold War Rationality, Chicago: University of Chicago Press, 2013. 
debates over algorithmic rationality. The two parts of this paper show that this definition arose in the intellectual milieu enthralled by human capacity to draw the limits of algorithmically solvable. Therefore, not only do the arguments based on Western materials not explain the Soviet actors' engagement in these Cold War developments, but we are losing valuable historical insights for establishing conversations between pedagogical and research communities preoccupied with computer literacy today.

The work of the Soviet school of mathematical logic did not travel across the Iron Curtain stripped to a mathematical definition. To recognize the Cold War as a project of not only preventing nuclear armageddon but of imagining a lasting peace shifts its stage from control rooms to classrooms. Algorithms in the Russian-language context, instead of being about reducing human thinking to computational procedures, fit with what one could call a humanist ideal of computer literacy. The particular relevance of this transformative dimension of Cold War algorithmic culture as the "culture of the impossible" is in strong connection with the present-day debates on computer literacy, politics of digital access, and computational thinking.

\section{Part I: Recovering Intelligentsia Logics}

Among the long list of sciences victimized by the Soviet regime, logic holds a place that emphasizes ruptures. Logic as a victim of the Stalinist marxist opposition to idealism is, however, a negative narrative with little explanatory power for understanding either the nature or the specificity of the rise of the Soviet school of mathematical logic from the 1950s on. Restoring the influences of the Russian imperial intellectual tradition in the field of logic across decades can elucidate the otherwise sudden emergence of preoccupations with reasoning, synthesis, and social responsibility taking the form of an educational utopia in the second half of the twentieth century. The connections we trace are composed of genealogical interpretations of ideas as well as resilient social practices of intelligentsia science.

Two parallel processes were responsible for the dominant narrative of discontinuity. One is a process of omission: pre-revolutionary logic had little chance to exercise direct influence internationally in times when numerous russophone scholars physically despaired in the cataclysms of wars and revolutions, removed by boat, by force, by exile, along with their philosophical and scientific ambitions between 1917 and 1930. They were also symbolically wiped from Western historiography as peripheral and not corresponding to the Fregean framework of mathematical logic that grew to be "standard" in the post-WWII period. ${ }^{13}$ Much as Western historiography gradually discarded thinkers who were too peripheral or incommensurate with the Fregean conception of logic, there was no reason why Russianlanguage texts too distant from the Fregean framework would have had a different fate. The second is a process of silencing: after the revolution, multiple strands of logic were first implicitly othered, and, by the end of 1920s, pronounced harmful. Formal logic specifically, accused of holding a metaphysical heritage irrelevant and deluding for the revolutionary proletariat, was pinned against the logic of dialectical materialism. ${ }^{14}$

13 Gottlob Frege, celebrated as the "forefather of modern logic," retains the legacy of eschewing all things psychological and subjective from modern logic, with his formalism and his notation. See Graham Priest, "Nineteenth Century German Logic," in The Oxford Handbook of German Philosophy in the Nineteenth Century, ed. K. Gjesdal M. Forster, Oxford University Press, 2015, 398-416.

14 Valentin Bazhanov, Istoriia Logiki v Rossii i SSSR [History of Logic in Russia and the USSR], Moscow: 
To recover the subtle connections in the realm of intelligentsia science ideas and social practices, Part I is organized in two sections. We start with a synthetic overview of the turn-of-the-century intellectual landscape connected to the conceptual category of poznaniye, focusing on three key aspects: the double role of educational practice as a site of personal formation but also of the investigation into the foundations of reasoning, including mathematical reasoning; the circulating mathematical object of the LEM as a means of discussing the limits of knowledge; and, finally, the debates on mechanization of reasoning and its performative functions. In the second section, we show that each of these themes endures and helps to explain the understanding of logico-mathematical tools as means to grapple with mathematical impossibilities. They reappear in novel, hybrid forms, both in the early Soviet debates criticising the so-called "bourgeois logic" as well as in the post-war period of institutional consolidation of mathematical logic. Although invisible to the standard historical tool of direct references, these themes can be recovered in close analysis of ideas and biographical details -- in circulating texts, in conceptual ingenuities, and in methodological peculiarities.

\section{1. Establishing Logical Pluralism: Poznaniye, LEM, and the Mechanization of Reasoning}

In order to provide a bird's-eye view of the 19th century intellectual landscape, we outline a number of threads holding together the body of works on symbolic codification of reasoning by russophone intellectuals. Despite being produced by a fairly small number of people, in distant parts of the vast Empire, pre-revolutionary logical investigations were socially situated as intellectually significant for the loose association of thinkers known as the intelligentsia. United by a shared sense of responsibility for the future of their country more so than by their political or philosophical views, the intelligentsia milieu linked the role of logic and the practice of natural sciences to the charged question of national destiny.

It is often thought that intellectual debates about the future of scholarship and culture in the Russian Empire had a binary nature: Russophilic vs Western-looking. ${ }^{15}$ The former was associated with a religious worldview, the latter with a secular one, and both relied on categories of classical logic as metaphors to paint their arguments. On the Russophilic side, for example, Ivan Kireevskiy depicted the Russian tradition as a willingly transrational opposition to the Aristotelian "iron chain of syllogism," while Nikolai Trubetskoi urged an acknowledgment of "the Romatic-Greek world [a]s our most bitter foe [...]."16

Between those two well-defined extremes, however, there was a large, dynamic, interactive space of logical investigations. In fact, the mediating role of the logical pluralism that we trace reinforces the recent scholarship which suggests that the "perceived divide between the religious narrative [in Russian philosophy] and its opposition is not as deep as initially assumed." ${ }^{17}$ The various syllogism-defying systems were messy, interweaving both Western and local, Russian-language ideas, often in combinations unique to each thinker. Rather than taking sides in that binary debate, the logical ideas of the intelligentsia

Canon+, 2007.

15 According to a simplified depiction of the camps, since the 1830s, the Slavophiles criticised the practice of importing political and economic institutions from the West in favor of policy preserving spiritual values and socioeconomic organization of the peasant community. They were opposed by Westernizers who believed that Russia shared historical destiny with the Western Europe and argued for political reforms leading to constitutional government and accelerated industrialization.

16 Kireevskiy and Trubetskoi, cited in A. DeBlasio, The End of Russian Philosophy: Tradition and Transition at the Turn of the 21st Century, Palgrave Macmillan, 2014, p.17. Note that Trubetskoi is disparaging the Ancient Greek and the Roman heritages of philosophy in general, of which logic is a substantive part.

17 Alyssa DeBlasio, The End of Russian Philosophy: Tradition and Transition at the Turn of the 21st Century, Palgrave Macmillan, 2014, p. 38. 
showcase that codifying reasoning for them came with grandiose ambitions about giving precision to particularly local aspirations for modernity in the Russian Empire, while also being mindful about their global relevance. Legitimizing different national agendas of social transformation, logic had acquired a function of synthesizing West-defying and West-following socio-political ambitions. When we envision intellectual exchanges spanning matters of reasoning and policy-making as belonging to the same "space in between," we can see the plurality of logics as fitting the late imperial reformist ferment at the intersection relating an individual's mind to the world out there.

The concept of poznaniye, translating most closely to the "process of acquiring knowledge," is the crucial category without which any understanding of this pluralism is impossible. Although ubiquitous in sources, it has literally been lost in translation in secondary literature. Amidst the baffling diversity of logical application and foundational interest, poznaniye was a uniting epistemic category upon which the majority of logical investigations in the late Russian Empire were centered. Etymologically related to knowledge (znaniye) and to consciousness (soznaniye), poznaniye was central to a number of disciplines and projects, which resemble Western epistemology, but with a gnoseological twist. "Epistemology," in fact, as a term, was encountered rarely, as was znaniye (knowledge), whereas "gnoseology" and poznaniye were common, dating back to a Greek distinction between gnosis ( $\gamma v \tilde{\omega} \sigma \iota \zeta)$ and episteme

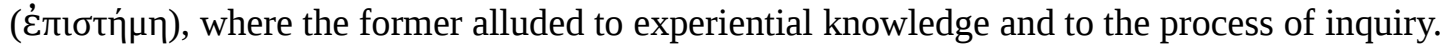

Turn-of-the-century intellectual discourse was filled with poznaniye-centric terms, and in particular two closely related terms, which were sometimes used interchangeably: nauka poznaniya, or the science of poznaniye, and medotologiya, or methodology. Much as the pluralistic logical investigations never formed an explicit school of thought, methodology as a field never cohered to a welldefined discipline. Nevertheless, methodological emphasis in logical investigations exposed a pervasive view, in which lawfulness was not considered as some abstract given, but where the act of learning theories was what brought lawfulness to life. Methodology materialized the value placed on one's virtuosic ability to interweave disparate methods and logics. Moreover, that some of those methods were inherently contradictory was not regarded as a sign of methodological error, but rather as adherence to common sense.

Perhaps unsurprisingly, the domain in which poznaniye commitments were most alive in logical research was the domain of education. The field of pedagogy was growing at a very fast pace to match the growing resources and admissions to education since the Great Reforms of the 1860s and in response to a new series of pedagogical reforms in the early twentieth century. Methodology was growing alongside, illustrating that how to teach very diverse populations, some of which had access to non-elementary education for the first time, was of practical concern. ${ }^{18}$ Around the 1910 s we observe that many secondary schools began to have Methodology courses attached to every subject: physics would come with "methodology of physics," and the same would be true for everything from geography to grammar. Methodology appears to have been a curious theory of practice.

Focusing exclusively on the pragmatic orientation, however, would misrepresent the profound intellectual ambitions behind methodological research, pertaining to the foundations of knowledge. Understanding how one acquired knowledge about a subject was regarded as a precondition for the possibility of knowledge-acquisition in the first place. ${ }^{19}$ For example, in the New Logic textbook (1898), the logician Nikolai Lange considers methodology to be a part of logic, though not completely separable

18 In the Russian Empire, between 1905 and 1913, the number of pedagogical institutes increased by 230\%; the number of gymnasiums for men increased by $67 \%$, for women by $121 \%$; and $1,184 \%$ more women were admitted to county schools. Between 1900 and 1914, the composition of the student body in universities changed immensely: while in 1900, 52\% of students were children of government officials and officers, by 1914 that number fell to $36 \%$. Statistics taken from reports by the National Ministry of Education, published in those years in St Petersburg; credit to A.I. Ivanov for making the statistical calculations.

19 This is consistent with a frequently-encountered critique of Kant. Logicians like Nikolai Grot, Sergei Povarnin, Kalistrat Zhakov, Aleksandr Shchukarev and others claimed that Kant took practice too far out of the question of logic, unjustly isolating the context of logical inquiry, the material conditions that enable it, and deyatel'nost' (activity) of poznaniye into the separate category, thereby rendering it "extra-logical." 
from either inductive or deductive branches. At the foundation of methodology is what he called the "postulate of learnability [poznavaemost']”: “[...] the world we study corresponds to the demands of our reasoning." ${ }^{20}$ Logical methods such as comparison, distinguishing, abstraction, definition, classification all for Lange rested on our ability to perceive sameness, difference, equality, or novelty in the world as a reflection of these properties in our perceptual capabilities. Note that this avoided the more common debate about whether mathematical objects were invented or discovered: ${ }^{21}$ Lange (and others) were pragmatically concerned with witnessing these reflections in learning experiences, in order to understand more deeply the process of knowledge-acquisition - poznaniye - itself. In this context, the performative dimension of educational materials or pedagogical reflections was illustrative of certain foundational logical thought experiments. Methodology and poznaniye were neither questions of mere individual intellectual curiosity, nor exclusively pragmatic responses to tumultuous times. They were problems of entangled practical, philosophical, and political relevance.

Every city had either a society, or individuals, or both, deeply committed to developing pedagogical methods for logic and mathematics. In Odessa, a popular lecturer on mathematics, Samuil Shatunovsky (1859-1929), was remembered by Chebotaryev as enacting an immersive performance in large, public lectures: Shatunovsky would dive into axiomatic rigor, without defining or explaining every term, from the very first day. ${ }^{22}$ Students were often puzzled, mystified, but also captivated by this possible world. ${ }^{23}$ In addition to large public lectures, Shatunovsky taught at a high school for Jewish women, as well as at the Novorossiyskiy University. In his research, he was deeply curious about the foundations of math and logic, and his enactment of mathematical poznaniye in lecture halls echoed the logicallymotivated opening to his 1917 algebra text: to establish an intuition about relatability of the logicomathematical objects discussed, without relying on abstraction to forge this connection. Together with three colleagues, Shatunovsky founded a popularizing journal titled Mathesis in Odessa in 1904, which functioned through 1925 and today might be described as a publication of "engaged learning" activities for mathematics and various sciences. Like Shatunovsky's lectures, these materials were not "simplified." Pedagogy and research were fundamentally entwined, exposing popularization as an expression of the intelligentsia's agenda, focused on individual minds and the future of society.

Another expression of the goal of creating a society of engaged individuals can be found in motivational speeches of the mathematician Nikolai Bugaev (1837-1903) that provide a good sense of popularizing discourses on the role of mathematics for the thinking population at large:

At the basis of mathematical truths lie such obvious axioms, that the very act of pointing to them may seem superfluous. [...]

Therefore, next to truths expressing properties and relations among magnitudes, there are truths characterizing inner operations of our spirit - facts of the inner world.

In the most natural way mathematics transitions to logic [...] concerning the limit of our poznaniye, properties of our reasoning, [and] validity [dostovernost']. [...]

Mathematics is the link, which we think connects the sciences of the outer world with the sciences of the inner world. ${ }^{24}$

20 N. Lange, Uchebnik Logiki [Logic Textbook], Odessa: M.S. Kozman, 1898, p.170. This and all following quotes in Part I and Part II, unless otherwise noted, are translated by the authors of this article.

21 For an example of analogical reasoning within modern cognitive sciences, see G. Lakoff, and R. E. Núñez, Where Mathematics Comes from: How the Embodied Mind Brings Mathematics into Being, New York, Basic Books, 2011.

22 Shatunovsky was the first to translate Georg Cantor's works into Russian.

23 N. Chebotaryev, "Samuil Osipovich Shatunovskiy (K 10-i letiiu so dnia smerti)" [Samuil Osipovich Shatunovskiy (On the 10th anniversary since his death)], Uspekhi Matematicheskikh Nauk [Russian Mathematical Surveys], vol. VII, 1940, pp. 316-321. Similar accounts of performativity hold for Luzin's mathematical circle of students known as Luzitania, of the early USSR' Moscow's School of Functions, see: L. Graham and J-M. Kantor, Naming Infinity: A True Story of Religious Mysticism and Mathematical Creativity, Cambridge, MA: Harvard University Press, 2009.

24 Nikolai Bugaev, "Matematika kak orudie nauchnoe i pedagogicheskoe (posvyashchaetsia pamyati Nikolaia 
In other words, mathematics' ultimate power lay not in being a tool of efficiency or productivity, but in its social power, namely, enabling a human capacity for synthesizing and interacting with the environment.

Bugaev's depiction of poznaniye-oriented ways in which logic interfaced with mathematics is effectively illustrated via the Law of Excluded Middle (LEM), or the Aristotelian-old claim that either A is $\mathrm{B}$, or $\mathrm{A}$ is not $\mathrm{B}$, and there is no middle option. ${ }^{25}$ The LEM appeared in discourse and in practice as a central mathematical object needing rethinking, in order to help deepen the landscape of contradictory results, and to productively handle impossible and contradictory scenarios. As a connecting thread across writings in different syntactic languages, by logicians of varied strands, the LEM presented a space of doubt, a soft spot of classical Aristotelian logic. Suspicion towards the LEM exposed the widespread assumption across russophone logicians that logicality must dip beneath lawfulness, and that formal logical systems must permit the emergence of lawfulness, without a pre-existing condition of noncontradiction, and with no restrictions of the permitted type of methodological interplay. In other words, the LEM-denying thought experiments answered to epistemological worries about process and coherence inherent to questions of poznaniye: asking how one acquires knowledge facilitated defiance of the binary notion of truth. ${ }^{26}$

This critique of this fundamental law of reasoning dates back to the early 19th century, when mathematician Orest Novitsky noted, "does it really make sense to say of a horse, that she is either a scholar or not a scholar?" ${ }^{27}$ While modern philosophy may call these worries "category mistakes," for the scholars within the Russian Empire the worry was about abstract derivatives from incomparable things. Moreover, Novitsky's early claim that "excluding the middle [option] denies transitions and middle [grounds] in between the opposites" foreshadows many turn-of-the-century attempts at improving the LEM by constructing process-based rather than proposition-based logics, as well as later interest in the definition of the algorithm. ${ }^{28}$

In application to mathematical proofs, rejection of the LEM led directly to rejecting proofs by contradiction, resembling what decades later would be termed "constructivism.” While the LEM figured in debates on the mathematical foundations in the West, a clear split between intuitionism's defiance of the LEM and Hilbert's and his followers' endorsement of "the legitimacy of proofs of existence by contradiction" did not take place in the Russian Empire. ${ }^{29}$ Instead, prior to the Revolution, an increasing plurality of logics thrived, each with its own treatment of contradictory information, turning the LEM into a peculiar circulating logical-mathematical object imbued with reflexivity on what logic could be in the first place.

If the LEM served as a thread connecting scholarship which insisted on the scientific integrity and intellectual potentiality of poznaniye in logic and math over questions about knowledge as such, another type of a circulating logico-mathematical object enabled a mechanical expression that rendered abstract laws tangibly visible. Stanley Jevons's Logic Piano, through the ways it was demonstrated, altered and discussed, illustrates the stakes of poznaniye in public science across the political divide of

Yefimovicha Zernova)," [Mathematics as a scientific and pedagogical tool (in the memory of Nikolai Yefimovich Zernov)] Matematicheskii Sbornik, vol. 3, no. 4, 1868, pp. 183-216.

25 Also known as the Law of Excluded Third. Note that in modern symbolic logic, the principle of bivalence (p v -p) is distinct from the LEM. Bivalence is a characterization of a logic, or an interpretation of a language, while the LEM is a rule of deduction. One can have a case where the law applies but the principle does not (e.g. Liar's paradox).

26 Rejection of the LEM, and resulting logical pluralism, was situated within a larger cultural trend of defying "classical” lawfulness, which was a feature of the Russian Silver Age (roughly 1890s-late 1920s). Parallel to denying the LEM, there were rampant thought experiments in defiance of Euclid's Fifth Postulate, or creative endeavors based in non-Eucliean Geometry, see: Linda Henderson, The Fourth Dimension and Non-Euclidean Geometry in Modern Art, Cambridge: MIT Press, 1983.

27 See O. Novitskiy, Rukovodstvo k Logike [A Guide to Logic], Kyiv: University Press, 1841.

28 The most notable process-based logics are "relational logics" of Nikolai Grot (1852-1899) and Sergei Povarnin (1870-1952).

29 L. Corry, The Rise of Algebraic Structures, Basel: Springer, 2004, p. 162. 
1917.

In 1913, Aleksandr Shchukarev - who modified and perfected the logical piano he inherited at Kharkiv University - published Problems in Theory of Poznaniye, which included a discussion of Jevons's logical machine. ${ }^{30}$ He claimed the piano to be instrumental to what he saw as the goals of methodology: to remove any assumed boundaries from the cognizing [poznayuscheye] self in the "eternal search for invariants in poznaniye.” His actual construction and enhancement of Jevon's Logic Piano, however, were preceded by an in-depth discussion of Jevons's machine by Ivan Sleszynski, a Polish mathematician living in Odessa at the turn of the century. In an 1893 text published for the popularizing mathematics journal VOFEM, Sleszynski walked the reader through every theoretical step of Boolean operations alongside each mechanical step of which part of Jevons's machine was to be engaged. Compared to Jevons's original article (1870), where the theory was presented first, and the construction of the machine was presented later, Sleszynski was interweaving this material for his audience with characteristic methodological theory-practice entanglement. Not only the public demonstrations of the machine but the texts were performative, with full aim of an immersive experience for the viewer or the reader. Shchukarev toured different cities with his machine and lectures until the late 1920s, attracting large audiences, but, as witnessed by the announcements and reports in press, his particular logical machine belonged to a larger discussion about mechanization of reasoning and mechanization of creativity.

Of particular interest was the area "psychotechnology" -- a "polydisciplinary program for studying the phenomenon of creativity." ${ }^{31}$ In his last work published in the Soviet Union before exile, Philosophy in innovation and innovation in philosophy (1922), philosopher and logician Ivan Lapshin set out to analyse the "mechanism of creativity" through a holistic theory of poznaniye. Although pessimistic about the immediate prospects of "psychotechnology" because of philosophical prejudices and cultural dualism separating reasoning and intuition, Lapshin espoused a positive agenda for realizing his study program. This wide ranging agenda was strongly experimentalist and encompassed a range of propositions from cooperation of different specialists such as doctors and technicians, to reverse engineering of innovators' products for the study of design processes, to research in simulacra, or illusions of philosophical and scientific creativity. The union of the creative and the technological, the fascination with and the encouragement of mechanistic reasoning was, however, only possible within human-centric values, embedded within what Lapshin called the "precious characteristics of being human." 32 If dismissive of the holistic details of a genuine creative process, we are, he said, only distracted by the "continuous intervention of dogmatic speculation." 33

Lapshin's framing of the discussion on mechanization of reasoning in connection to creativity helps elucidate public critique of Shchukarev's logical machine that otherwise might be dismissed as an ideological one. In the 1924 issue of the journal Under the Banner of Marxism, the logician Ivan Orlov denounced Shchukarev's performances as deluding the public. ${ }^{34}$ Orlov argued that while his machine

30 A. Shchukarev, Problemy teorii pozaniya [Problems in Theory of Poznaniye] Odessa: Mathesis, 1913. Shchukarev was preceded by Pavel Khruschev, also a chemistry professor at Kharkiv University, who constructed his own version of Jevons's machine. Shchukarev's modifications (since 1911) included adding a tableau and enabling the machine to display possible conclusions rather than only the correct one. This was both for didactic reasons and to relegate to the machine something the human cannot do with such awareness - the full space of possible choices rather than the weighted, "logical" choices. Moreover, these modifications were implemented for better visibility, highlighting the performative aspect of the demonstration.

31 Lana Dulaeva, Problema "Izobreteniya v filosofii" v koncepcii I. I. Lapshina [The problem of "innovation in philosophy" in Ivan Lapshin's conception], PhD Thesis, Moscow, 2005, p.7.

32 Ivan Lapshin, Filosofiya Izobreteniya i Izobretenie v Filosofii: Vvedenie v Istoriyu Filosofii [Philosophy in innovation and innovation in philosophy: Introduction to the History of Philosophy], Mysliteli XX Veka, Moskva: Izd-vo "Respublika," 1999, p.338. (Reprinted from 1922).

33 Ivan Lapshin, Filosofiya Izobreteniya, p.339.

34 I. Orlov, "O ratsionalizatsii umstvennogo truda" [On the rationalization of intellectual labor], Pod Znamenem Marksisma [Under the Banner of Marxism], no. 12, 1926, pp. 72-92. The use of the term "rationalization" in 
made attempts to include induction by exposing all possible outcomes in a deductive system, it did not mechanize poznaniye. At the same time, Orlov was not against mechanizing the most basic aspects of human reasoning. Like Lapshin, he emphasized that this was not to replace humans with machines, but to liberate humans from the menial, basic tasks, so that more of their time could be dedicated to productive, higher order creativity. ${ }^{35}$ Shchukarev, however, in Orlov's view, fell short of living up to his standard of "the foundation and forms of the acts of reasoning must be found in the process of poznaniye itself." 36 Although the close reading of Shchukarev's own descriptions of what cannot be mechanized show that contradictions between the two scholars were superficial, this turned out to be of little relevance, as by the end of the 1920s, both Shchukarev's and Orlov's respective engagements in public science and philosophy of knowledge waned and the machine was eventually lost. ${ }^{37}$

The traces of the logical machine performances and the debates on creativity and mechanization are, however, invaluable for helping situate the association between the mechanical and the human during the 1950s. Also revived in the postwar years was the pre-revolutionary treatment of logic as a framework for foundational experimentalism, but the continuities were made inconspicuous, demanding an exercise in deciphering and decoding from a historian.

\section{2. Decoding Transmission}

The key events in the process of institutionalization of mathematical logic in the Soviet Union took place in the late 1950s. The 3rd All-Union Mathematical Congress held in 1956 featured a cluster of some fifty papers on mathematical logic and became a platform for claiming a better institutional status for the field. The creation of the special department at the Steklov Mathematical Institute of the Soviet Academy of Sciences in 1957 and a new chair at the department of mathematics of the Moscow University in 1959 met the demands. By the early 1970s, the discipline acquired a mainstream standing with compulsory classwork for all students of the mathematical department, grounded upon the definition of mathematical logic as a branch of mathematical knowledge devoted to study of mathematical propositions by mathematical methods.

This definition of mathematical logic came accompanied by a corresponding version of history. In the talk on "Mathematical Logic in the Former Soviet Union: Brief History and Current Trends," delivered at the international conference in the 1990s, and therefore no longer constrained by any official ideology or even local memory politics, Vladimir Uspensky lists a few pre-revolutionary contributions as "pre-history," including the medieval scholar Al Khwarizmi, and spares no space for complex institutional and ideological underpinnings. In a characteristic statement on Sophia Yanovskaya (1896-1966) and her role in the field, he recognized her managerial, not intellectual, contributions: "She made no research in ML by her own, but deserves credit for making it possible for others." ${ }^{38}$ While Uspensky makes no mention of the turn-of-the-century logical investigations, we connect them here to the institutional consolidation of the field of mathematical logic in the 1950s by co-locating the embodied experiences of Kolmogorov, Markov, and Yanovskaya within their formative milieus. This exercise not only reveals continuities across the 1930s mathematical work apparently unrelated to logic, but, no less significantly, elucidates the relation between Yanovskay's ideas and her role as a community builder.

That a generation of the Soviet mathematicians, who were born around the turn of the century

particular situates Orlov's criticism in close relation to the official ideological discourse.

35 I. Orlov, "O ratsionalizatsii umstvennogo truda” [On the rationalization of intellectual labor]. pp. 72-92, on p. ?

36 Aleksandr Shchukarev, Problemy, p.ii.

37 According to one recent interpretation, Shchukarev's disengagement was not provoked by Orlov but by local conflicts that led to his 1931 retirement from the Kharkiv University where he was teaching physical chemistry. V. V. Shilov and S. A. Silantiev, "Reasoning vs. Orthodoxy, or, The Lesson from the Fate of Russian 'Reasoning Machine’," in IFIP International Conference on Human Choice and Computers, Springer, Berlin, Heidelberg, 2014, pp. 191-202.

38 Vladimir Uspensky, "Mathematical Logic in the Former Soviet Union: Brief History and Current Trends," in Logic and Scientific Methods, Springer, Dordrecht, 1997, pp. 457-483, on p. 459. 
were exposed to the field of pozaniye in general and LEM in particular could be overlooked not only due to different geographical and institutional locations, but due to the various logical languages in which they expressed the disciplinary unison of these LEM-defying works. For instance, changing the LEM to a construction where there are three choices and no fourth option (ie, Law of Excluded Fourth) was something both Nikolai Vasiliev (1880-1940) and Ivan Orlov (1886-1936) did, but the connection is hardly obvious, given that Vasiliev was working in the language of syllogisms, while Orlov in modern symbolic logic. Similarly, Pavel Florensky (1882-1937) used modern symbolic notation to construct a proof of antinomy (which he translated syntactically as $\neg \mathrm{p} \supset \mathrm{p} \supset \mathrm{p}$ ), while Ivan Lapshin was constructing a descriptive logic for uniting opposing epistemic views that had barely any symbolic encoding; yet, both were committed to constructing LEM-rejecting logics in which the background notion of truth did not have to be binary (true or false). Instead, the only sensible background assumption was the "necessary self-contradictory [nature] of reason." 39

In Western historiography, rejection of the LEM is associated with Brouwer's intuitionistic logic. Indeed, interest in Brouwer's thinking was widespread, but the pre-Soviet intellectual preoccupation with the LEM is not reducible to the Brouwerian reference. In particular, although the 1925 paper "On the Principle of Tertium Non Datur" by Kolmogorov does explicitly contend with Brouwer's thoughts, it should not be classified as "intuitionistic," since the treatment of the LEM is more subtle. A fresh graduate aged twenty-two, Komogorov presents the LEM as a valid mathematical operation in relation to "pseudo-truth" and an invalid one in relation to actual truth. ${ }^{40}$ Though this paper is often mentioned as the "beginning” of mathematical logic in the Soviet Union, it is best understood as belonging to a particular moment when questioning the universality of the LEM was a norm. Kolmogorov's differentiation between truth and "pseudo-truth" was analogous to other thinkers who employed the LEM as a contextspecific logico-mathematical object: in the case of Vasiliev - there was logic and metalogic, in the case of Lapshin - logic and superlogic, and Yanovskaya in the 1920s, Grot in the 1880s and Novitsky in the 1820s - all considered the LEM to be a marker of delusion rather than a marker of lawfulness. That is, continuous with Kolmogorov's distinction between "pseudo-truth" and truth, other russophone logicians preceding him committed to a distinction - in which the LEM played a key role - between empirical and superempirical realities. ${ }^{41}$

The case of Markov Jr's "normal” algorithm is similar. ${ }^{42}$ That the construction of the "normal" algorithm as a mathematical object was conceived and articulated in reaction to the Western work on logically equivalent but different concepts in the 1930s is obvious from the text and lists of references in Markov's works. But this dialogue does not exclude a local genealogy as reflected in the LEM. Though constructive mathematics can be understood as "mathematics done without the law of excluded middle," 43 the reverse also holds true: these earlier LEM-centric concerns were analytically coterminous to what later became termed "constructivism," since rejection of LEM leads to rejection of proofs by contradiction and thus rejection of appeal to the "abstraction of actual infinity" -- a rhetoric dating back to the early 1920s.

39 Pavel Florensky, The pillar and ground of the truth: an essay in orthodox theodicy in twelve letters, trans. Boris Jakim (Princeton, N.J.: Princeton University Press, 2004), p.153.

40 A. Kolmogorov, “On the Principle of Tertium Non Datur,” Mat. Sb, 32(4), (1925), pp. 646-667, p.646.

41 As G. S. Smirnova points out, the use of "pseudo-" as a prefix was employed by other mathematicians and was not exclusive to Kolmogorov. See Galina Smirnova, "At the Moscow's Mathematical Front: From the History of Reorganization of the Moscow Mathematical Society in 1930,” Voprosy Istorii Estestvoznaniia i Tekhniki 41, no. 2, 2020: 280-310, on p. 285.

42 A. A. Markov, Teoriia algorifmov, Trudy MIAN SSSR 42, Moscow: Izd-vo AN SSSR, 1954, translated as Theory of Algorithms (Jerusalem: The Israel Program for Scientific Translations, 1961).

43 Andrej Bauer, "Five Stages of Accepting Constructive Mathematics," Bulletin of the American Mathematical Society 54, no. 3, 2016: 481-98, on p. 481. Note that while Markov's algorithm is not provable from within intuitionistic logic, a restricted domain of conclusions does allow for a conditional invocation of the excluded middle when applying the Markov principle. See https://arxiv.org/pdf/1611.03714.pdf. 
In contrast to Markov and Kolmogorov, retracing continuity in Yanovskaya's activities in mathematical logic is simultaneously straightforward, as her organizational contributions were acknowledged, and challenging. To appreciate Yanovskaya as a thinker demands a different type of skill in decoding ideas, namely dealing with a difficult question of ideology and its discourse. It is in Yanovskaya's writing that we find Lenin's “This is the essence of dialectics, expressed by the formula: unity, equivalence of opposites'” that illustrates how challenges to the LEM could be coupled with a validation of Hegelian dialectics. ${ }^{44}$ But how to interpret this curious example amalgamating Lenin with the LEM for understanding Yanovskay's role in the institutionalization of mathematical logic in the 1950s?

As a notable student of Shatunovsky, Sophia Yanovskaya expresses the tensions of what Vasiliev Sr., following the 19th century tradition, called the intelligentsia's task of living "historically engaged lives" in connection to the intellectual agenda of mathematical logic in the Soviet context. In the absence of a full biographical study, the studies and memoirs devoted to Yanovskaya are notoriously contradictory, as different aspects of her life seem too much to handle: not only a rare female mathematician, Yanovskaya was a Jew; neither a passive witness to nor victim of revolutionary struggles, she was at the frontline beside her husband as the Red Army's political commissar; in Moscow of the early 1920s she took part in the seminars by the leaders of the Moscow mathematical school but publicly turned against them in the 1930s, taking active part in the so-called "Luzin affair"; finally, referred to as a "mathematician without theorems," she was the editor of Marx's mathematical manuscripts, is known as Wittgenstein's interlocutor, and is credited with creating the Soviet schools of both the history of mathematics and of mathematical logic. A recent overview of her work concludes with a call against segregating the political and the academic in her life, an attitude that we share. ${ }^{45}$ Although answering this call systematically is beyond our task here, we highlight several episodes involving Yanovskaya as related to ideas and values associated with algorithmic thinking.

Reading Yanovskaya's published work for traces of cultural transmission and continuity with prerevolutionary figures is no simple task. In a subtle twist of intellectual and political commitments, she integrated the research agenda and mobilized examples that circulated within the pre-revolutionary communities of scholars and aficionados of logic and mathematics in a fight against "bourgeois idealism" of the first post-revolutionary decades. One of her publications devoted to mathematical abstraction in Under the Banner of Marxism published in 1935 -- the same year that she obtained her doctoral degree and hosted Wittgenstein in Moscow and a year before she took part in a public accusation of Luzin -illustrates how the pre-revolutionary questions about mathematical knowledge and Marxism could come together.

In "On the so-called definitions via abstraction,” Yanovskaya argues against exceptionalism of mathematical knowledge as grounded in an idealist understanding, to offer a materialist philosophy, history, and anthropology of the foundational notions in mathematics. ${ }^{46}$ Although the comparison of genesis of natural numbers to Marx's theory of money places Yanovskaya's approach within dialectical materialism, the very title of the article and the substance of her mathematical illustrations reveals debts to Shatunovsky's work on algebraic number theory and on foundations of logic. For instance, her argument against “definition by abstraction” bears much resemblance to Shatunovsky's concerns about appeal to abstraction as a result of unjustified invocation of the LEM. Without referencing her former teacher, Yanovskaya performs the same theoretical argument as Shatunovsky’s "logical unity,” using

44 S. A. Yanovskaya, "Predislovie k russkomu perevodu” [Preface to the Russian Translation], Vvedenie v logiku i metodologiiu deduktivnykh nauk, by A. Tarski, Moscow: Gosudarstvennoe Izdaniie Inostrannoi Literatury, 1948, pp. 5-18, on p. 13. Note that before the Revolution, too, Hegel and the dialectical method were popular, and not only among revolutionaries. The point here is that the pre-Soviet LEM-rejecting efforts were not necessarily centered on Hegel, even if in conversation with his works.

45 Dimitris Kilakos, "Sofia A. Yanovskaya: The Marxist Pioneer of Mathematical Logic in the Soviet Union,” Transversal: International Journal for the Historiography of Science, no. 6 (2019): 49-64.

46 S. Yanovskaya, “O tak nazyvaemykh 'opreledelniiakh cherez abstraktziiu'” [On the so-called definitions via abstraction], Pod Znamenem Marksisma, no. 12 (1926), pp. 154-179. 
some of the same examples as he did (e.g., Dedekind's cut) to illustrate her point, which amounts to a logical precondition: for all instances of mathematical objects in formulaic relation (e.g., equality), they must be subject to comparison in the first place. ${ }^{47}$ As an example of a valid comparison, she offers comparison by modulo in number theory, which -- again without reference -- is the subject of Shatunovsky's entire 200-page text that follows after establishing "logical unity.” Like Shatunovsky, in cases where validity for comparison cannot be established, she argues that carrying out comparison would be an unjustified appeal to abstraction. Unfortunately for the historian, in addition to omitting direct references, Yanovskaya's writing is sufficiently infused with dialectical theorizing and with emphasis on historical genesis, that witnessing the mathematical and the methodological continuities to pre-Soviet scholarship -- here Shatunovsky's -- is a laborious process demanding the researcher's immersion into earlier texts. The very recognition of the seriousness and deep roots of her intellectual project, however, sheds light on Yanovskay's organizational and pedagogical engagements.

To correct Uspensky’s formula, Yanovskaya was both intellectually invested in mathematical logic and made its study possible for others. In this light, both her 1925 seminar on the methods of mathematics and natural sciences (attended by Kolmogorov among many other young mathematicians), and her 1930 course on the history of mathematics, obtain larger significance and coherence. These activities reflected an intellectual vision interlocking knowledge about methods and about the history of mathematics that is, in turn, related to the key institutional development in mathematical logic in the aftermath of World War II -- the seminar she conducted with P. Novikov starting in 1947. Although the teaching of logic was reintroduced in the Soviet secondary school following Stalin's 1946 decree, the pivotal moment in the history of the seminar is better understood in a local conjuncture. The death of I. I. Zhegalkin (1869-1947), under whose authority the seminar was conducted previously, led to its relocation to the chair of the history of mathematics. ${ }^{48}$ Founded and headed by Yanovskaya, this chair served as an institutional home to the growing numbers of students, such as Uspensky, working on mathematical logic.

The recollections reveal that the seminar was more than episodic meetings of people with similar interests. The seminar became a mechanism of community building by creating a community of trust bound by shared practices of scientific communication in a decade preceding the institutionalization of the late 1950s. For instance, its working style was described as "democratic and informal" and clarity in exposition and in writing were habits to acquire and to reproduce in the participants' own teaching practice. ${ }^{49}$ Moreover, the seminar also acted as a coalition for negotiating what was ideologically acceptable and intellectually valid. The community role was maintained even after the graduates went off to teach at provincial universities, as illustrated by the situation faced by B. Trakhtenbrot, who defended his thesis under P. Novikov in 1950.

When he became embroiled in a local conflict, attacked by his colleagues at the mathematical department at the Penza Pedagogical Institute, Trakhtenbrot called upon his Moscow mentors. At the source of the discord was Trakhtenbrot's 1951 lecture titled "The Method of Symbolic Calculi in Mathematics," in which he justified the need for an exact definition of the intuitive concept of "algorithm." Although Trakhtenbrot deliberately used "symbolic calculi" instead of "formal logic," in order to avoid association with the ideologically compromised term of "formalism," this tactic was insufficient to prevent a more general accusation of holding a "neutral position in the dispute between

47 Samuil Shatunovsky, Algebra kak ucheniie o sravneniiakh po funktsional'nym moduliam [Algebra as the study of comparison based on functional modules], Odessa: Tekhnik, 1917, pp. ii-viii. Yanovskaya’s invocation of Dedekind's cut also comes with an ideological (for her, towards anyone potentially "bourgeois") critique of Dedekind, but the logical point she illustrates remains faithful to Shatunovsky.

48 Author of works on mathematical logic, the foundations of mathematics, and set theory, Zhelakin is best known for demonstrating that all Boolean operations could be written as ordinary numeric polynomials, representing the false and true values as 0 and 1, the integers mod 2. See: I. I. Zhegalkin, I. I. "O tekhnyke vychyslenyi predlozhenyi v symbolytscheskoi logykye," [On the technique of calculating propositions in symbolic logic] Math. Sb. 34 (1927), pp. 9-28.

49 B. Trakhtenbrot, “In memory of S. A. Yanovskaya (1896--1966) on the Centenary of Her Birth,” Modern Logic 7, no. 2 (1997), pp. 160-187, on p. 161. 
materialism and idealism in mathematical logic." ${ }^{50}$ Yanovskaya took on the main burden of Trakhtenbrot's defense.

The preserved correspondence demonstrates the coexistence of what may appear as two contradictory modes. On the one hand, Yanovskaya produced official documents grounded in her authority as a red professor advising a younger colleague on the ideological interface between the mathematical and philosophical aspects, as well as guiding him through the party-state ritual of selfcriticism. But, on the other hand, the writing style of the correspondence reproduces social conventions cultivated by intelligentsia and built on the paramount relation of interpersonal trust. This observation illustrates that social mechanisms and values of intelligentsia science precluded neither understanding of Marxism nor administrative acumen when encountering dogmatism in the context of the anticosmopolitan campaigns of late Stalinism. Fortunately for Trakhtenbrot, the confrontation ended in a validation of his work, expressed through an invitation issued by the Moscow seminar to write a survey article on the subject, motivated by a lack of work explaining algorithms for the broader mathematical community. This relatively minor event thus is significant not so much for its consequences but for revealing the processes of community building which translated interpersonal trust into a collective validation of intellectual agendas. The episode also demonstrates that the community solidarity and institutional networks that helped institutionalize the field in the second half of the 1950s did not come into place on their own. Yanovskaya was pivotal in this process socially, institutionally, and intellectually.

In the end, Trakhtenbrot did not respond to the seminar's invitation to write for the prestigious Mathematical Surveys. Instead, his 1956 overview article first appeared in Mathematics in School, and was expanded to a book form in 1957, leading to several editions and an English translation in $1963 .{ }^{51}$ His text did not discriminate between teachers of mathematics and researchers, serving as an early example of the efforts to render the notion of algorithm widely accessible. Although enhanced by the 1955 acknowledgement of the Soviet work on computers, Trakhtenbrot's pedagogical agenda is actually in direct relation to the controversial 1951 lecture. His discussion of the notion of algorithmic unsolvability touched upon a philosophical question: is there a general deciding algorithm for the whole of mathematics? In this way, this widely circulated work also belonged to a wider conversation sitting at the intersection of academic research and popular writing since the turn-of-the-century debates about codification of reasoning.

Yanovskaya's preface to the Russian translation of Turing’s 1950 "Can Machines think?” published in 1960 reveals the ongoing contestation of a non-dialectical understanding of human consciousness as well as of mechanistic reduction. Although situated in a very different ideological context of the Thaw, further discussed in Part II, the very substance of Yanovskaya's reading of Turing is significant. In her eyes, the interest of Turing's question is not related to machine intelligence but to that of humans: the real question behind whether a machine can think is in fact a question about whether human consciousness operates algorithmically. She opposes Turing's idea of a learning machine with a marxist-leninist description of a dynamic consciousness. This dialectical framework, however, echoes a familiar issue of knowledge acquisition:

...the very essence of poznaniye is a process, every step of which -- including any list of natural laws -- features only an approximation, a non-complete character. Such a list can enable an imitation of human behaviour by the machine, and even entail a potential expansion of such imitation as its limits cannot be defined in advance. Nevertheless, this does not imply the existence of an ideal machine, the programm of which represents a full list of natural laws of human thinking that are fixed once and forever. ${ }^{52}$

50 Trakhtenbrot, “In memory of S. A. Yanovskaya (1896-1966),” p. 166.

51 B. Trakhtenbrot, Algoritmy i mashinnoe reshenie zadach, Moscow: Gostekhizdat, 1957, 1st ed.; B. Trakhtenbrot, Algorithms and Automatic Computing Machines, Boston: D.C. Heath and Company, 1963.Altogether, the book circulated globally, translated in a dozen of languages.

52 S. Yanovskaya, "Predisloviye k russkomu perevodu," in Can Machines Think?, by A Turing, Moscow: GosIzdatel'stvo Fiz-Mat Literatury, 1960, §5. 
In other words, it is impossible to claim that human thinking could be reduced to algorithmic thinking based on the algorithmic character of the rules of logic. Two implications of this understanding are of interest here: one is in relation to the perceived tasks of mathematical logic, another to training human, not machine, minds.

Different contemporaneous texts help elucidate the first issue. Yanovskaya's introduction to Overview on mathematical logic and foundations of mathematics (1959) -- a text edited by her and relying on Uspensky's documentation of Moscow's seminars devoted to recent works on the theory of algorithms -- says the following of the pertinence of mathematical logic: "when the problem refuses to be solved stubbornly, when the theorem can neither be proved nor disproved, when the algorithm cannot be found." 53 Similarly in his 1954 monograph, Markov argued that his definition of the algorithm, including its definiteness, generality, and conclusiveness, is pertinent to methodology and the theory of knowledge that he situated within the human mind itself, and not within the machine. "The research, knowledgeproducing functions in mathematics (as in any other science) will never be transferred to machines," insisted the Soviet mathematician, "only able to help the human, but not to replace him." 54 How a negative definition of algorithmic thinking came to acquire the positive meaning of understanding what is solvable and unsolvable algorithmically in connection to pedagogical projects and programming practice is a subject for further exploration that we begin in the next part.

In concluding Part I, we emphasize that mathematics and logic were culturally construed as essential instruments in the toolbox for exploring the limits of knowledge, within and outside of the scope of "the mathematical," and coded by moral valences of serving society. We argue that the influences of this turn-of-the-century aspiration can be seen decades later as it consolidates in the definitions of the algorithm and in the interplay between the research and pedagogical agenda of cybernetics and programming as well as more broadly in the late Soviet visions of information society as examined in Part II.

53 Quoted after 1960 English translation: S. Yanovskaya, ed., Overview on Mathematical Logic and Foundations of Mathematics, New York: JPRS, 1960, p. 4.

54 A. A. Markov, Teoriia algorifmov, Trudy MIAN SSSR 42, Moscow: Izd-vo AN SSSR, 1954, translated as Theory of Algorithms (Jerusalem: The Israel Program for Scientific Translations, 1961), p. 372. 